conditions such as hip replacement were lengthening long before the consultant work-to-rule. Emigration of doctors, already increasing, will certainly speed up further if nothing is done to reverse the decline of N.H.S. standards of care. Time is not on our side. Discussions are needed, now, about the economic alternatives for the N.H.S. in the lean years ${ }^{6}$ we have certainly got ahead. Decision is urgent.

1 The Times, 6 February, 1975.

${ }^{2}$ British Medical fournal, 1974, 4, 272.

British Medical Fournal, 1975, 1, 297.

4 Biggs, R., Lancet, 1974, 1, 1339.

5 British Medical fournal, 1975, 1, 251.

${ }^{6}$ British Medical fournal, 1975, 1, 297.

\section{Brain Death}

North American surgeons are no longer willing to transplant a kidney removed after the donor's heart has stopped beating: legal opinion there apparently holds that such an operation would be negligent, in that the chances of success would be lower than if the kidney had come from a "beating-heart cadaver." A meeting held at the Royal Postgraduate Medical School last week to discuss brain death was told of this current American view, and the point was reinforced by Mr. G. Chisholm's question "Would you choose to be given a living kidney or a blue, mottled one removed after warm ischaemia of 45 minutes or more ?" Good quality cadaver kidneys are obtainable only in cases where brain death occurs before the heart stops, and the surgeon removes the organs while they are still being oxygenated.

Brain death can be diagnosed on clinical grounds without the use of electroencephalography or carotid angiography, said Dr. C. Pallis. Firstly, the clinician must exclude the possibility that the coma was due to hypothermia or drug overdosage. Next, there should be no spontaneous respiration over a period of three minutes observation, and no spontaneous movementdecerebrate or epileptic. No brain-stem reflexes should be present. The pupils must be dilated; the corneal, ciliospinal, and gag reflexes absent; and there should be no response to firm supraorbital pressure. The eyes should remain in constant relation to the head when the head is moved-no "doll's head" eye movement, lagging behind the rotation of the head, should occur. There should be no ocular deviation in response to ice-cold water poured into one ear; and the tonic neck reflexes should be absent.

If all these tests were unequivocal on two occasions 12 hours apart then the brain stem was dead, said Dr. Pallis. The tendon jerks in the limbs might be present or absent, or they might be absent one day and present the next; but these findings had no bearings on the diagnosis or prognosis. One further point added by Dr. B. MacGillivray was that the clinician should be reasonably certain of the condition responsible for the brain damage, and it should be one known to be fatal. There were rare cases in which the brain stem remained alive after the cortex had been destroyed by, for example, a gunshot wound. In such circumstances spontaneous respiration and heartbeat might continue for days or weeks. While medically speaking there might be no doubt about brain death, the general opinion seemed to be that such a diagnosis would not be acceptable to the patient's relatives.

The gulf between the medical and public concepts of death is clearly likely to remain a problem for some time; several of the medical staff spoke of the reluctance of relatives to consent to removal of organs from a patient whose heart was still beating. Such natural anxieties, sometimes reinforced by religious beliefs, must be respected if doctors are to retain the confidence of their patients.

\section{"British Journal of Obstetrics and Gynaecology",}

The initial appearance of the Fournal of Obstetrics and Gynaecology of the British Empire in January 1902 was justified editorially by the need for a special journal, independent of any society, to present a complete and impartial record of British work. As well as expounding British obstetrical and gynaecological practice it was to provide a summary of contemporary thought and achievement in obstetrics and gynaecology throughout the world. Special prominence would be given to original essays by experienced workers in the United Kingdom and in the British Dominions beyond the seas, but a considerable part of each number was to be set aside for "abstracts of the writings of American and foreign authorities." The first issue comprised 128 pages and included an analysis of 100 cases of uterine fibromyoma and a paper on spinal anaesthesia.

The journal was well received and supported but became a great war casualty in 1915. It was resurrected in quarterly form in 1921. Since then it has reflected some of the medical and political changes inside and outside the British Isles. In 1961 "Commonwealth" was substituted for "Empire" in the title. Since 1968 its appearance has been (appropriately) monthly. The multiplicity of new journals caused the discontinuance of the "Review of Current Literature" in 1971. The current issue brings a further change of title to the British Fournal of Obstetrics and Gynaecology. Though, as formerly, it is published under the direction of the Royal College of Obstetricians and Gynaecologists it is much more than a "house journal." We are confident that under the present editor, Frank Loeffler, who like his first predecessor, Alban Doran, is attached to the Samaritan Hospital in London, our contemporary will maintain its high standards and continue to attract and publish contributions from all over the world.

\section{Surgery of Violence}

At page 382 this week the B.M.F. publishes the first of a short series of articles under the general title, Surgery of Violence. Though the troubles in Ireland have provided the surgical experience on which the series is based, doctors above all will fervently hope that the present truce will lead on to lasting peace. But those are not the only disturbances to cause injuries of this kind, for, as the authors of the first article rightly point out, "Urban guerilla warfare seems to have become a part of life (and death) in the 1970s. ..."

Owing to the sporadic nature of many of the attacks by explosive weapons the doctors who must deal with the victims are apt to be inexperienced in the management of such cases. We have therefore invited some surgeons and physicians in Northern Ireland, who have unhappily had so much recent experience of treating wounded patients, to record important lessons and to give advice to colleagues. The articles will appear weekly over the next few issues. 